\title{
Urethral skip metastasis from cancer penis or a second malignancy? A dilemma!
}

\author{
Rohit Kathpalia, Apul Goel, Bhupendra Pal Singh \\ Department of Urology, Chhatrapati Shahuji Maharaj Medical University, Lucknow
}

A 76-year old man presented with stricture of bulbar urethra for which he underwent urethral dilatation and was advised to perform self urethral dilatation. Four months later he noticed an ulcerative lesion over glans penis and its biopsy revealed a verrucous carcinoma. This was managed by partial penectomy. The resection margins were free of tumor. Two months following surgery, the patient again developed poor urinary stream. Physical examination revealed normal urethral meatus and there was a hard swelling in midperineal area suggestive of urethral calculus. Retrograde urethrogram showed an irregular filling defect in peno-bulbar urethra (Figure-1).

Cystoscopy was inconclusive as only one surface of the lesion was visible and that too was covered by slough. In view of advance age and localized excisable disease, the patient underwent wide excision of the mass with permanent perineal urethrostomy. The histopathological examination of the mass showed hyperkeratinised stratified squamous epithelium showing acanthosis and papillomatosis suggestive of verrucous carcinoma (stage T2).

\section{COMMENTS}

He underwent successful management of penile tumor with tumor free margins. Subsequent urethral involvement (skip lesion) in penile cancer is uncommon. It is known that urethral tumors usually arise in areas of urethral stricture (1). Whether this patient developed an independent second malignancy or whether it was a metastasis from penile cancer is debatable as tumors at both these sites are squamous in nature. However, metastasis seems more likely because of the short interval of only 2-months between partial penectomy and the development of the urethral lesion. Some etiologic factors for penile as well as urethral cancers are similar like HPV infection (2). However, we could not find any report of co-association between these two cancers in the literature.

Urethral cancer is an uncommon condition. The presentation is varied and includes urethral bleed, obstructed urinary flow or perineal urethrocutaneous fistula (3). The investigation of choice is controversial although most investigators today believe that MRI is the best imaging modality in these cases (4). We also had a similar experience and found that the MRI images (Figure-2) were much superior to the CT scan. The patient was managed by wide local excision which is standard therapy for localized disease.

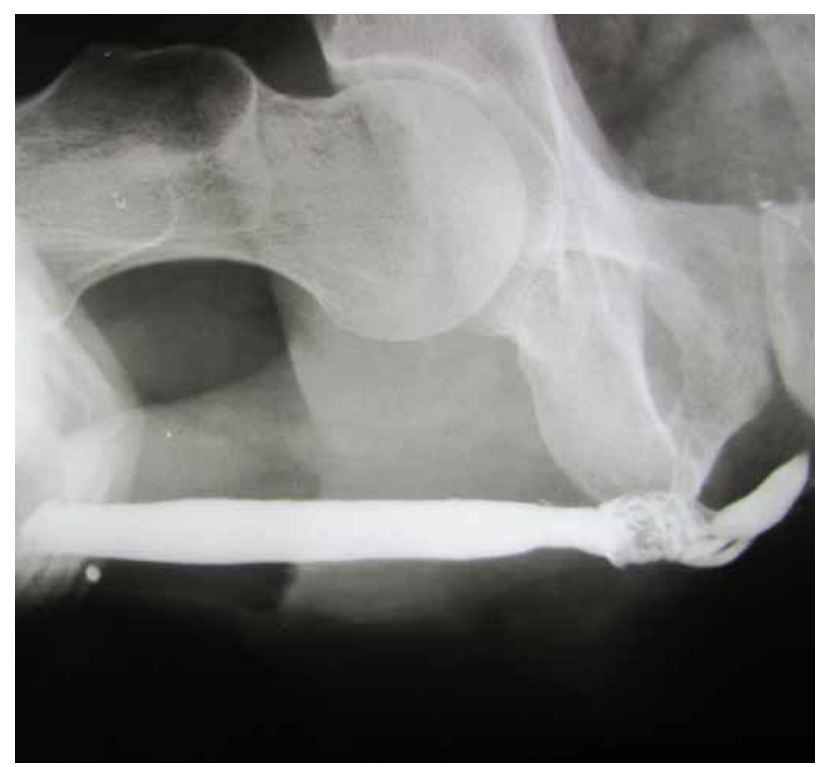

Figure 1 - Retrograde urethrogram shows irregular contrast filling in the penobulbous urethra. 

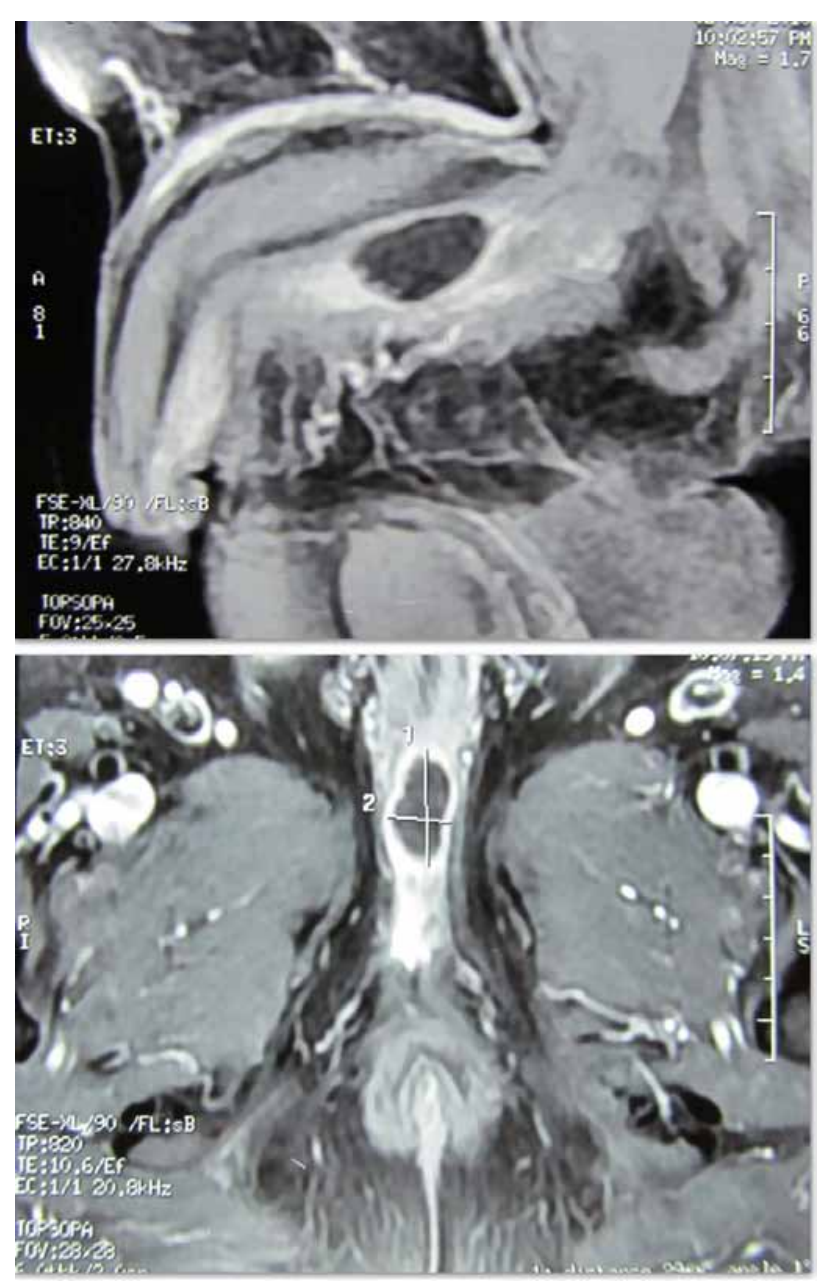

Figure 2 - MRI urethra shows a lesion displaying heterogenous signal intensity alterations isointense on T1 WIs and hypointense on T2 WIs in peno-bulbous urethra with mild peripheral post-contrast enhancement.

\section{REFERENCES}

1. Dalbagni G, Zhang ZF, Lacombe L, Herr HW: Male urethral carcinoma: analysis of treatment outcome. Urology. 1999; 53: 1126-32.

2. Varma VA, Sanchez-Lanier M, Unger ER, Clark C, Tickman R, Hewan-Lowe K, et al.: Association of human papillomavirus with penile carcinoma: a study using polymerase chain reaction and in situ hybridization. Hum Pathol. 1991; 22: 908-13.

3. Ramada Benlloch F, Eres Sáez F, Gonzalvo Pérez V, Navalón Verdejo P, Sabater Marco V, Marqués Vidal E, et al.: Primary carcinoma of the male urethra: review of the literature and presentation of a new case. Arch Esp Urol. 1992; 45: 565-8.

4. Vapnek JM, Hricak H, Carroll PR: Recent advances in imaging studies for staging of penile and urethral carcinoma. Urol Clin North Am. 1992; 19: 257-66.

\author{
Correspondence address: \\ Dr. Apul Goel \\ Professor, Dept of Urology \\ Chhatrapati Shahuji Maharaj Medical \\ University, \\ Formerly King George Medical College, \\ Lucknow, 226003, India \\ Fax: + 91983 918-1465 \\ E-mail: goelapul1@rediffmail.com
}

